\title{
Therapeutic effects of nintedanib are not influenced by emphysema in the INPULSIS trials
}

\author{
To the Editor:
}

Emphysema is a common comorbidity in patients with idiopathic pulmonary fibrosis (IPF) [1-4]. Due to the combination of restrictive and obstructive effects, patients with concomitant IPF and emphysema typically present with normal or elevated forced vital capacity (FVC) but reduced diffusing capacity [5]. Data from retrospective studies have demonstrated that lung function decline is attenuated in patients with IPF who have emphysema [6], with some evidence suggesting a threshold for extent of emphysema beyond which FVC decline is reduced [7].

Nintedanib is a tyrosine kinase inhibitor approved for the treatment of IPF. In the two Phase III INPULSIS trials, nintedanib reduced disease progression by reducing the annual rate of decline in FVC (the primary end-point) versus placebo (difference of $109.9 \mathrm{~mL} \cdot \mathrm{year}^{-1}$, 95\% CI 75.9-144.0, based on pooled data) [8]. Based on pooled data, nintedanib was associated with numerical but not statistically significant benefits on the key secondary end-points of time to first investigator-reported acute exacerbation and change from baseline in St. George's Respiratory Questionnaire (SGRQ) total score over 52 weeks [8]. To participate in the INPULSIS trials, patients were required to have an FVC $\geqslant 50 \%$ predicted, a forced expiratory volume in $1 \mathrm{~s}(\mathrm{FEV} 1) / \mathrm{FVC}$ ratio of $\geqslant 0.7$ and a diffusing capacity of the lungs for carbon monoxide (DLCO) 30-79\% predicted. The presence of emphysema (yes/no) at screening was determined by qualitative assessment of high-resolution computed tomography (HRCT) scans by a single expert radiologist.

We investigated whether the presence of emphysema, or the degree of airway obstruction assessed by FEV1/FVC ratio, at baseline influenced the treatment effect of nintedanib in the INPULSIS trials. In post $h o c$ analyses, the primary analyses of the primary and key secondary end-points (described in [8]) were repeated in subgroups of patients with versus without emphysema at baseline and with a baseline FEV1/ FVC ratio $\geqslant 0.7$ and $\leqslant 0.8$ versus $>0.8$ (a threshold chosen arbitrarily). For the primary end-point, the term subgroup and the interaction terms treatment-by-subgroup, time-by-subgroup and treatment-by-time-bysubgroup were included in the model. For the key secondary end-points, the term subgroup and interaction term treatment-by-subgroup were included in the model. Absolute change from baseline in composite physiologic index (CPI) over 52 weeks was also assessed in these subgroups. The CPI is calculated based on per cent predicted values for FVC, DLCO and FEV1 and correlates with extent of fibrosis on HRCT, irrespective of the presence of emphysema [9].

Of the 1061 patients treated in the INPULSIS trials, 420 (39.6\%) had emphysema based on qualitative assessment of an HRCT scan (yes/no) and 412 (38.8\%) had a baseline FEV1/FVC ratio $\leqslant 0.8$ at baseline. Baseline characteristics were generally similar between the subgroups by emphysema at baseline and by FEV1/FVC ratio $\leqslant 0.8$ versus $>0.8$ at baseline, except for a higher proportion of males and ex-/current smokers in the subgroups with emphysema and with an FEV1/FVC ratio $\leqslant 0.8$. The effect of nintedanib on FVC decline was consistent between patients with or without emphysema at baseline. In patients with emphysema at baseline, the adjusted annual rate \pm SE of decline in FVC was $-105.1 \pm 18.8 \mathrm{~mL} \cdot \mathrm{year}^{-1}$ with nintedanib and $-207.2 \pm 23.2 \mathrm{~mL} \cdot \mathrm{year}^{-1}$ with placebo (difference of $102.0 \mathrm{~mL} \cdot \mathrm{year}^{-1}$, 95\% CI 43.2-160.9) while in patients without emphysema, it was $-118.8 \pm 13.4 \mathrm{~mL} \cdot \mathrm{year}^{-1}$ with nintedanib and $-234.2 \pm 16.4 \mathrm{~mL} \cdot \mathrm{year}^{-1}$

@ERSpublications

In post hoc analyses of pooled data from the INPULSIS trials, the treatment effect of nintedanib versus placebo was not influenced by the presence of emphysema (yes versus no) or by FEV1/FVC ratio $(\geqslant 0.7$ to $\leqslant 0.8$ versus $>0.8$ ) at baseline http://ow.ly/Gmwn30nwPY1

Cite this article as: Cottin V, Azuma A, Raghu G, et al. Therapeutic effects of nintedanib are not influenced by emphysema in the INPULSIS trials. Eur Respir J 2019; 53: 1801655 [https://doi.org/10.1183/ 13993003.01655-2018]. 
Patients $n$

No emphysema at baseline, nintedanib Emphysema at baseline, nintedanib No emphysema at baseline, placebo Emphysema at baseline, placebo

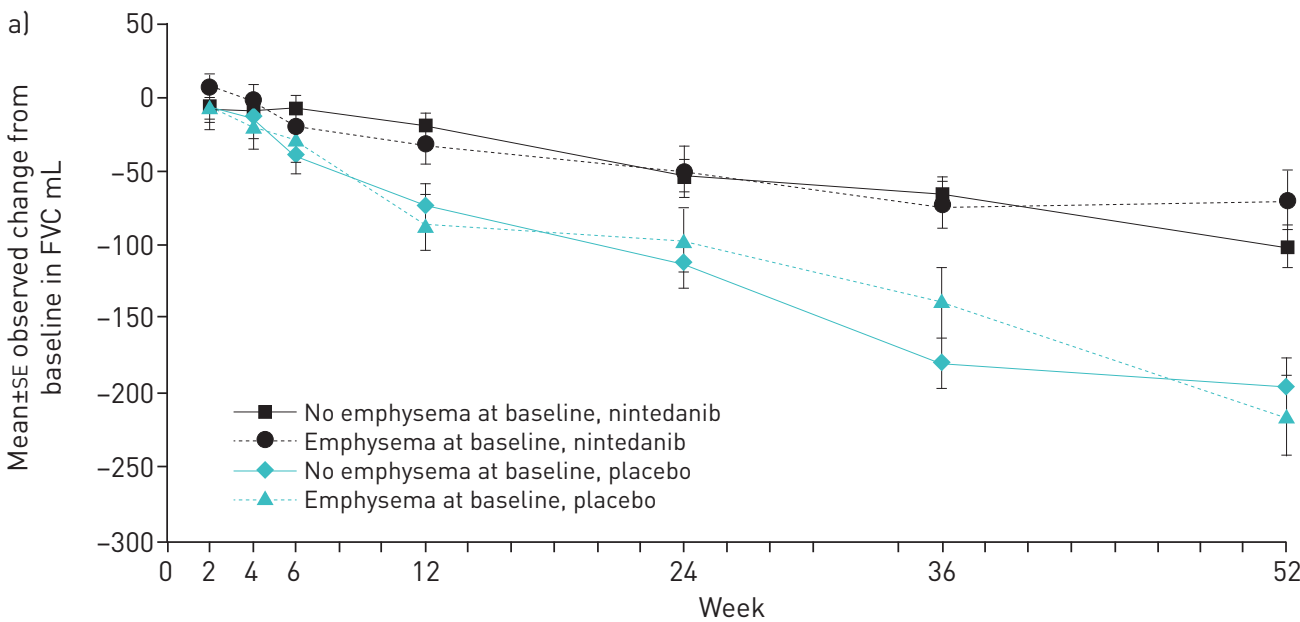

\begin{tabular}{|c|c|c|c|c|}
\hline 379375372 & 366 & 359 & 349 & 16 \\
\hline 247241241 & 238 & 228 & 220 & \\
\hline 252248245 & 246 & 244 & 236 & \\
\hline 165160162 & 157 & 151 & 147 & \\
\hline
\end{tabular}

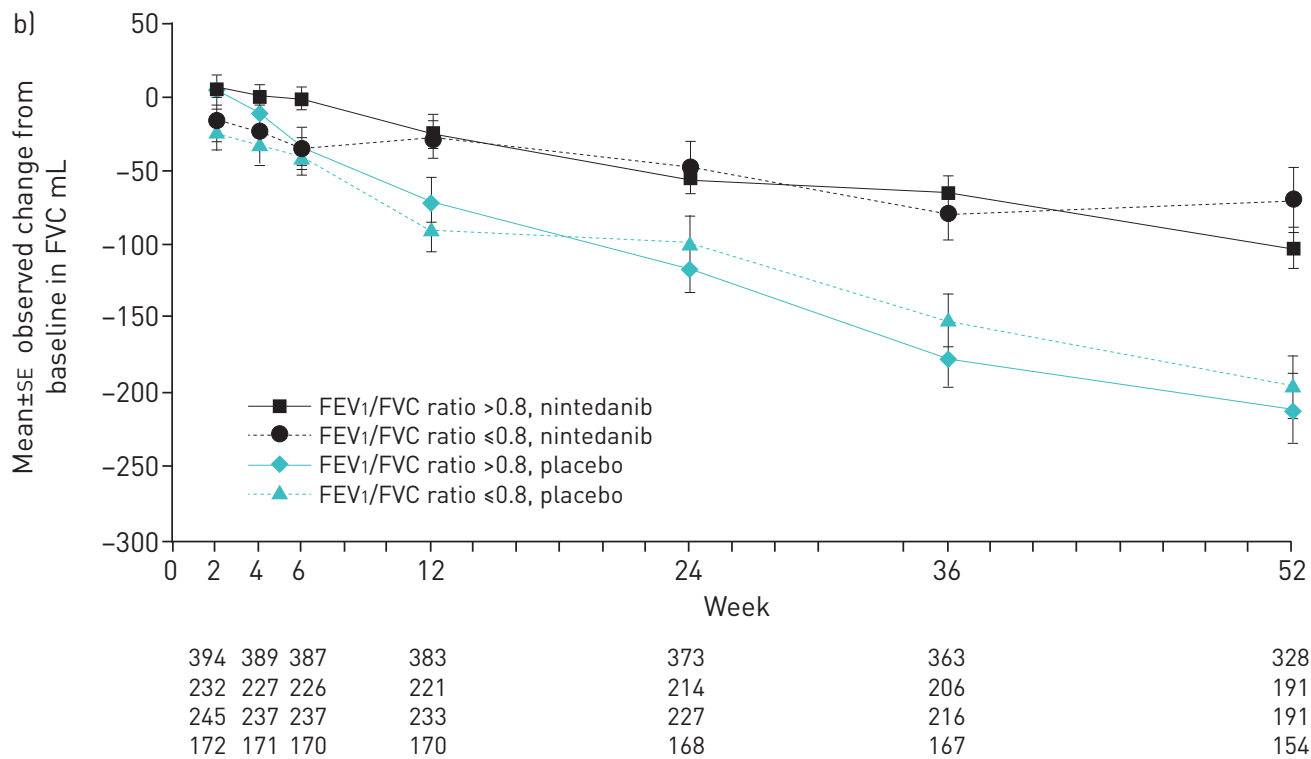

FIGURE 1: Mean \pm SE observed change from baseline in forced vital capacity (FVC) over time in subgroups of patients by a) presence of emphysema at baseline and b) forced expiratory volume in $1 \mathrm{~s}$ (FEV1)/FVC ratio at baseline.

with placebo (difference of $115.4 \mathrm{~mL} \cdot \mathrm{year}^{-1}$, 95\% CI 73.8-157.1) (treatment-by-time-by-subgroup interaction $\mathrm{p}=0.6771$ ). The effect of nintedanib on FVC decline was consistent between patients with a baseline FEV1/ FVC ratio $\leqslant 0.8$ versus $>0.8$. In patients with an $\mathrm{FEV} 1 / \mathrm{FVC}$ ratio $\leqslant 0.8$, the adjusted annual rate \pm SE of decline in FVC was $-88.6 \pm 18.1 \mathrm{~mL} \cdot \mathrm{year}^{-1}$ with nintedanib and $-184.0 \pm 20.3 \mathrm{~mL} \cdot \mathrm{year}^{-1}$ with placebo (difference of $95.5 \mathrm{~mL} \cdot \mathrm{year}^{-1}, 95 \%$ CI $41.9-149.1$ ) while in patients with an $\mathrm{FEV}_{1} / \mathrm{FVC}$ ratio $>0.8$, it was $-128.1 \pm 13.8 \mathrm{~mL} \cdot \mathrm{year}^{-1}$ with nintedanib and $-254.2 \pm 17.9 \mathrm{~mL} \cdot \mathrm{year}^{-1}$ with placebo (difference of $126.1 \mathrm{~mL} \cdot \mathrm{year}^{-1}$, 95\% CI 81.6-170.6) (treatment-by-time-by-subgroup interaction $\mathrm{p}=0.3735$ ). Consistent results were observed for changes from baseline in FVC over time (figure 1). In patients with emphysema at baseline, the adjusted mean \pm SE change from baseline in CPI was $3.5 \pm 0.7$ with nintedanib and $3.4 \pm 0.8$ with placebo (difference of $0.2,95 \% \mathrm{CI}-1.5-1.9$ ); while in patients without emphysema, it was $2.5 \pm 0.6$ with nintedanib and $4.3 \pm 0.7$ with placebo (difference of $-1.9,95 \% \mathrm{CI}-3.5--0.3$ ) (treatment-by-subgroup interaction $\mathrm{p}=0.2328$ ). In patients with an $\mathrm{FEV} 1 / \mathrm{FVC}$ ratio $\leqslant 0.8$, the adjusted mean \pm SE change from baseline in CPI was $3.0 \pm 0.8$ with nintedanib and $3.6 \pm 0.8$ with placebo (difference of $-0.7,95 \% \mathrm{CI}$ -2.4-1.1); while in patients with an FEV $1 / \mathrm{FVC}$ ratio $>0.8$, it was $2.7 \pm 0.5$ with nintedanib and $4.4 \pm 0.7$ with placebo (difference of $-1.6,95 \% \mathrm{CI}-3.2-0.0$ ) (treatment-by-subgroup interaction $\mathrm{p}=0.8797$ ). 
In patients with emphysema at baseline, acute exacerbations occurred in $2.8 \%$ and $7.2 \%$ of patients treated with nintedanib and placebo, respectively. In patients without emphysema at baseline, acute exacerbations occurred in $6.3 \%$ and $7.8 \%$ of patients treated with nintedanib and placebo, respectively. The hazard ratio for time to first acute exacerbation was 0.36 (95\% CI 0.14-0.91) in patients with emphysema and 0.82 (95\% CI 0.45-1.49) in patients without emphysema at baseline, but the treatment-by-subgroup interaction was not significant $(\mathrm{p}=0.1449)$. The effect of nintedanib on reducing the risk of a first acute exacerbation was not significantly different between patients with a baseline $\mathrm{FEV} 1 / \mathrm{FVC}$ ratio $\leqslant 0.8$ versus $>0.8$ (treatment-by-subgroup interaction $\mathrm{p}=0.6118$ ). The hazard ratio for time to first acute exacerbation was 0.79 (95\% CI $0.28-2.25)$ in patients with an FEV1/FVC ratio $\leqslant 0.8$ and 0.57 (95\% CI $0.33-1.00)$ in patients with an $\mathrm{FEV} 1 / \mathrm{FVC}$ ratio $>0.8$. Acute exacerbations occurred in $3.0 \%$ and $4.0 \%$ of nintedanib- and placebo-treated patients with an $\mathrm{FEV} 1 / \mathrm{FVC}$ ratio $\leqslant 0.8$, and $6.0 \%$ and $10.1 \%$ of nintedanib- and placebo-treated patients with an FEV1/FVC ratio $>0.8$.

The effect of nintedanib on change in SGRQ total score was consistent between patients with or without emphysema. Nintedanib- and placebo-treated patients with a baseline FEV1/FVC ratio $>0.8$ had a numerically greater increase (worsening) in SGRQ total score (4.43 and 7.27 points, respectively) than nintedanib- and placebo-treated patients with a baseline FEV1/FVC ratio $\leqslant 0.8$ (1.95 and 2.16 points, respectively). Between-group differences in change from baseline in SGRQ total score were -1.71 points (95\% CI -4.32-0.90) in patients with emphysema and -1.23 points (95\% CI -3.39-0.92) in patients without emphysema (treatment-by-subgroup interaction $\mathrm{p}=0.7723$ ). Between-group differences in change from baseline in SGRQ total score were -0.21 points (95\% CI $-2.71-2.29$ ) in patients with a baseline FEV $1 / F V C$ ratio $\leqslant 0.8$ and -2.83 points $(95 \% \mathrm{CI}-5.04--0.63)$ in patients with a baseline FEV1/FVC ratio $>0.8$ (treatment-by-subgroup interaction $\mathrm{p}=0.1251$ ).

In conclusion, in post hoc analyses of pooled data from the INPULSIS trials, the treatment effect of nintedanib was not influenced by the presence of emphysema or by FEV1/FVC ratio at baseline. These findings are consistent with previous subgroup analyses of the INPULSIS trials showing that the effect of nintedanib is consistent across subgroups of patients by thresholds of FVC at baseline [10,11] and across subgroups defined based on other baseline characteristics [12-15]. Interpretation of our findings is limited by the lack of an assessment of the extent or distribution of emphysema or fibrosis on HRCT at baseline. Further research is warranted into the potential impact of emphysema on FVC decline in patients with IPF.

Vincent Cottin $\oplus^{1}$, Arata Azuma $\odot^{2}$, Ganesh Raghu ${ }^{3}$, Wibke Stansen ${ }^{4}$, Susanne Stowasser ${ }^{5}$, Rozsa SchlenkerHerceg $^{6}$ and Martin Kolb $\oplus^{7}$

${ }^{1}$ National Reference Center for Rare Pulmonary Diseases, Louis Pradel Hospital, Hospices Civils de Lyon, Claude Bernard University Lyon 1, Lyon, France. ${ }^{2}$ Nippon Medical School, Tokyo, Japan. ${ }^{3}$ University of Washington, Seattle, WA, USA. ${ }^{4}$ Boehringer Ingelheim Pharma GmbH \& Co. KG, Ingelheim am Rhein, Germany. ${ }^{5}$ Boehringer Ingelheim International $\mathrm{GmbH}$, Ingelheim am Rhein, Germany. ${ }^{6}$ Boehringer Ingelheim Pharmaceuticals Inc., Ridgefield, CT, USA. ${ }^{7}$ McMaster University, Hamilton, ON, Canada.

Correspondence: Vincent Cottin, Louis Pradel Hospital, Claude Bernard University Lyon 1, National Reference Center for Rare Pulmonary Diseases, Pulmonology, 28 Avenue du Doyen Lepine, F-69677 Lyon cedex, France. E-mail: vincent. cottin@chu-lyon.fr

Received: Aug 302018 | Accepted after revision: Jan 032019

Acknowledgements: The authors acknowledge the contribution of David M. Hansell, formerly of the Department of Radiology, Royal Brompton and Harefield NHS Foundation Trust, London, UK, for reading the HRCT scans in the INPULSIS trials. Medical writing assistance, supported financially by Boehringer Ingelheim, was provided by Julie Fleming and Wendy Morris of FleishmanHillard Fishburn, Ltd., London, UK, during the preparation of this article. The authors were fully responsible for all content and editorial decisions, were involved in all stages of manuscript development, and approved the final version.

Conflict of interest: V. Cottin reports personal fees and non-financial support from Actelion (consultancy, lecture fees and travel to medical meetings), grants, personal fees and non-financial support from Boehringer Ingelheim (development of educational presentations, consultancy. lecture fees, travel to medical meetings and grant to institution), personal fees from Bayer/MSD (consultancy), personal fees from Gilead (member of adjudication committee), personal fees from GSK (consultancy), personal fees from Novartis (consultancy and lecture fees), grants, personal fees and non-financial support from Roche (consultancy, lecture fees, travel to medical meetings and grant to institution), grants from Sanofi (coordinator of trial), personal fees from Promedior (chair of DSMB), personal fees from Celgene (DSMB), and personal fees from Galapagos (consultancy), outside the submitted work. A. Azuma reports personal fees from Boehringer Ingelheim (advisory board member for clinical trial), during the conduct of the study; grants and other from Boehringer Ingelheim (steering Committee member of another trial), outside the submitted work. G. Raghu reports other from BI (consultant for IPF studies and for this trial), during the conduct of the study; grants from NIH (principal investigator for IPF net studies and steering committee member for IPF net studies), Bellerophan (consultant for IPF studies), Biogen (consultant for IPF studies), BMS (consultant for IPF studies), Fibrogen (consultant for IPF studies), Gilead (consultant for IPF studies), Nitto (consultant for IPF studies), Patara (consultant for IPF studies), Promedior (consultant for IPF studies), Sanofi (consultant for IPF studies), Veracyte (consultant for IPF studies), 
outside the submitted work. W. Stansen has nothing to disclose. S. Stowasser is an employee of Boehringer Ingelheim International $\mathrm{GmbH}$, the marketing authorisation holder of Ofev (nintedanib). R. Schlenker-Herceg is an employee of Boehringer Ingelheim. M. Kolb reports grants and other from Boehringer Ingelheim (funded the clinical trial and provided support for medical writing), during the conduct of the study; grants and personal fees from Roche, Boehringer Ingelheim, GSK and Prometic, personal fees from Gilead, Genoa, Indalo and Third Pole, and grants from Actelion, Respivert, Alkermes and Pharmaxis, outside the submitted work.

Support statement: The INPULSIS trials were funded by Boehringer Ingelheim. Funding information for this article has been deposited with the Crossref Funder Registry.

\section{References}

1 Behr J, Kreuter M, Hoeper MM, et al. Management of patients with idiopathic pulmonary fibrosis in clinical practice: the INSIGHTS-IPF registry. Eur Respir J 2015; 46: 186-196.

2 Ryerson CJ, Hartman T, Elicker BM, et al. Clinical features and outcomes in combined pulmonary fibrosis and emphysema in idiopathic pulmonary fibrosis. Chest 2013; 144: 234-240.

3 Cottin V, Nunes H, Brillet PY, et al. Combined pulmonary fibrosis and emphysema: a distinct underrecogised entity. Eur Respir J 2005; 26: 568-593.

4 Jacob J, Bartholmai BJ, Rajagopalan S, et al. Functional and prognostic effects when emphysema complicates idiopathic pulmonary fibrosis. Eur Respir J 2017; 50: 1700379.

5 Behr J, Furst DE. Pulmonary function tests. Rheumatology (Oxford) 2008; 47: Suppl. 5, v65-v67.

6 Akagi T, Matsumoto T, Harada T, et al. Coexistent emphysema delays the decrease of vital capacity in idiopathic pulmonary fibrosis. Respir Med 2009; 103: 1209-1215.

7 Cottin V, Hansell DM, Sverzellati N, et al. Effect of emphysema extent on serial lung function in patients with idiopathic pulmonary fibrosis. Am J Respir Crit Care Med 2017; 196: 1162-1171.

8 Richeldi L, du Bois RM, Raghu G, et al. Efficacy and safety of nintedanib in idiopathic pulmonary fibrosis. $N$ Engl J Med 2014; 370: 2071-2082.

9 Wells AU, Desai SR, Rubens MB, et al. Idiopathic pulmonary fibrosis: a composite physiologic index derived from disease extent observed by computed tomography. Am J Respir Crit Care Med 2003; 167: 962-969.

10 Costabel U, Inoue $\mathrm{Y}$, Richeldi L, et al. Efficacy of nintedanib in idiopathic pulmonary fibrosis across prespecified subgroups in INPULSIS. Am J Respir Crit Care Med 2016; 193: 178-185.

11 Kolb M, Richeldi L, Behr J, et al. Nintedanib in patients with idiopathic pulmonary fibrosis and preserved lung volume. Thorax 2017; 72: 340-346.

12 Taniguchi $\mathrm{H}, \mathrm{Xu} \mathrm{Z}$, Azuma A, et al. Subgroup analysis of Asian patients in the INPULSIS trials of nintedanib in idiopathic pulmonary fibrosis. Respirology 2016; 21: 1425-1430.

13 Raghu G, Wells AU, Nicholson AG, et al. Effect of nintedanib in subgroups of idiopathic pulmonary fibrosis by diagnostic criteria. Am J Respir Crit Care Med 2017; 195: 78-85.

14 Kreuter M, Costabel U, Richeldi L, et al. Statin therapy and outcomes in trials of nintedanib in idiopathic pulmonary fibrosis. Respiration 2018; 95: 317-326.

15 Costabel U, Behr J, Crestani B, et al. Anti-acid therapy in idiopathic pulmonary fibrosis: insights from the INPULSIS trials. Respir Res 2018; 19: 167. 